IOSR Journal of Engineering

e-ISSN: 2250-3021, p-ISSN: 2278-8719,

Vol. 2, Issue 12 (Dec. 2012), ||V3\|| PP 01-04

\title{
Role of Software Engineering in Blood Bank Management Information System
}

\author{
Vikas Kulshreshtha ${ }^{1}$, Dr. Sharad Maheshwari ${ }^{2}$ \\ ${ }^{1}$ Research Scholar, Singhania University Jhunjhunu, (Raj), India \\ ${ }^{2}$ Associate Professor, Govt. Engineering College Jhalawar, (Raj), India
}

\begin{abstract}
This paper tells the role of software engineering in blood bank management information system. Any software development cannot be possible without software engineering. In this paper researcher discuss the various models used in the software engineering. Researcher has used the Linear Sequential Model for the development of the Management Information System of blood bank, this model is also known as waterfall model. Researcher also discuss the various phases used in the model and also the implementation of these phases in the development of blood bank management information system.
\end{abstract}

Keywords: Software Engineering, Blood Bank, Management Information System.

\section{INTRODUCTION}

Software Engineering plays a vital role in the software application development. In the world of information, where the world has become a global village, computer software is become driving force. It becomes the part of day- today life of the common man. Human being can't think life without computer software. It serves for the mankind whether it is scientific research or engineering problem solving. It is a key factor that differentiates modern products and services. It is embedded in the system of all kinds of transportation, medical, telecommunication, military, industrial process, entertainment, office products and many more. And as well more in it will become the driver for new advance in everything from elementary education to genetic engineering.

Conceptually in the thesis researcher develops the web based application for the blood bank. In which he controls the inventory management, so that the stock keeping of the number of units stored in the blood bank is properly managed. This application provides the unique identification number and the contact information of the volunteer donor who registers online and also to that person who is donating the blood at the donation camp, so that at the time of blood unit crisis the staff members can contact the donor which is helpful in saving the life of the patient. Researcher also put emphasis on the information retrieval process of the blood bank. This feature helps to improve the efficiency of the blood bank and reduces the time to retrieve the information. The respondents of this research are the pathological department of the district hospital and hospitals situated in different community health centres (CHC). No need to say about the beneficiaries of the research. The application which is developed by the researcher will be helpful to all those people who have the requirement of the blood.

The development of the application can be done by using the various models in the software engineering. There are six models used in the software engineering, which are as follows:

1. Linear Sequential model: It is also sometimes referred as "waterfall model" or the classical life cycle. This model follows the systematic, sequential approach to software development.

2. Prototyping Model: When your customer has a legitimate need but he is clueless about the details, develop the prototype first. The above mentioned statement is the baseline for prototyping model. Brooks suggest the prototyping model. It often happens that customer is confused with input functions and the desired output. In this situation developer provide the prototype design to the customer which is based on the initial conversation between developer and customer. This model is based on the information gathered by the developer from the customer. The prototype ${ }^{[1]}$ is evaluated by the customer or client and used to refine requirement for the software to be developed.

3. RAD Model: It stands for "Rapid Application Development Model" as the name suggests RAD model is helps to develop the software quality. The time span of RAD model is about 60 to 90 days. In other words, RAD is the "high speed" of linear sequential model. If the definition, requirement are understood and project scope is constrained, RAD process creates the "fully functional system" within a very short span of time RAD consists the follows phases ${ }^{[2]}$.

4. Incremental Model: Incremental model is the mixture of linear sequential model and prototyping model ${ }^{[3]}$. It consist the elements of linear sequential model and adopt the iterative technique of prototype 
model. This model implements linear sequential model in a staggered fashion. When an incremental model is reused, the first increment is often a core product which results understanding of basic requirement, but many supplementary features are still unknown. Now the developer goes for the next increment by addressing the core product in order to meet the need of the customer in a better way. This process repeatedly goes on by the delivery of each increment, until complete product is produced. The incremental model is iterative in nature just life prototype model, but unlike prototype, the incremental model focused on the delivery of an operational product with each increment. Early increments show the capability to serve the user and provide the platform for evaluation for the user.

5. Spiral Model: Spiral model, originally proposed by Boehm ${ }^{[4]}$ is an evolutional software development model which is created by combining the potential approaches of linear sequential software mode and prototype model. Using spiral model, software is created in the form of incremental release.

6. The Win-Win Spiral Model: The win-win spiral model is based on the negotiation between the developer and customer. Mostly it is observed that customer is not able to discuss all the issues of the software widely. Boehm's win-win spiral model ${ }^{[5]}$ defines a set of negotiation activities at the beginning of each pass around the spiral.

The development of the blood bank management information system researcher has used Linear sequential model as it very simple and efficient. Linear sequential model has various phases which the researcher has followed for the development of the blood bank management information system, which are as follows:

$\begin{array}{ll}- & \text { Analysis } \\ \text { - } & \text { Design } \\ \text { - } & \text { Code } \\ \text { - } & \text { Test }\end{array}$

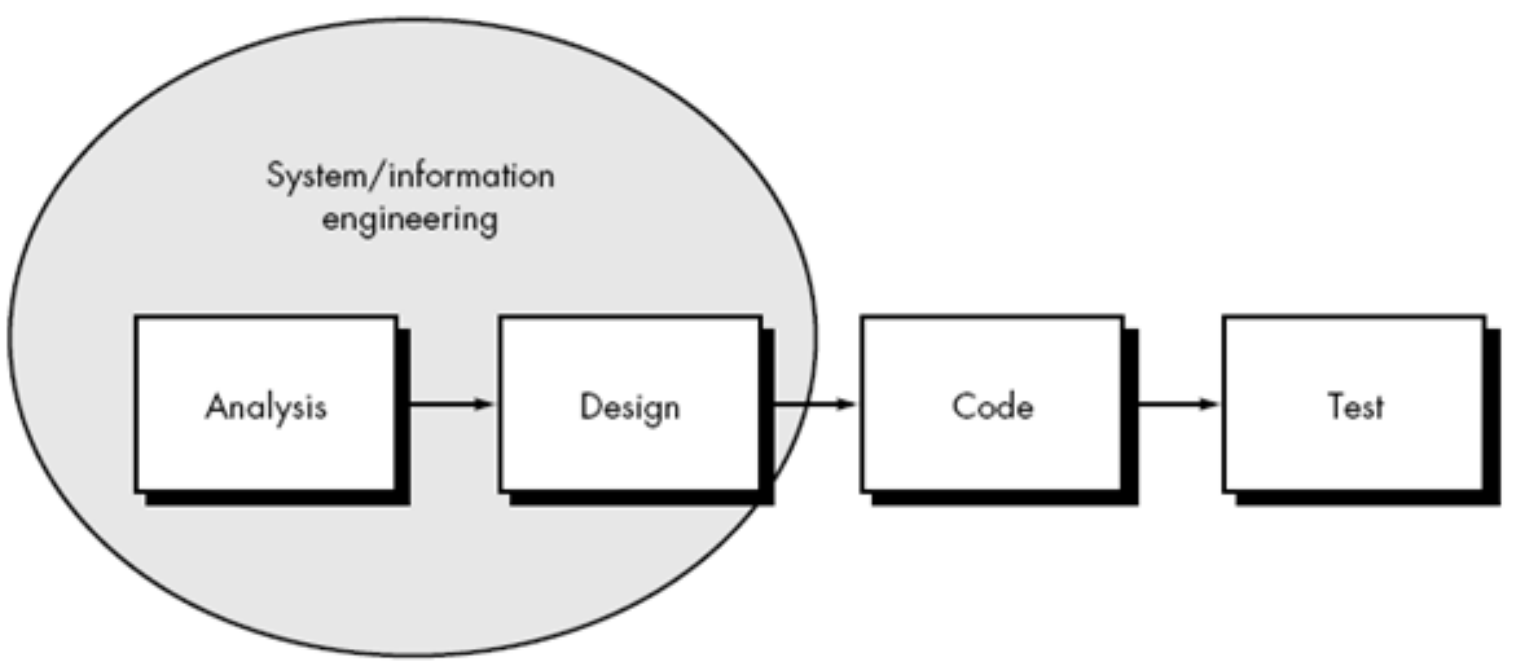

The description of the implementation of above mentioned phases in Blood Bank Management Information System are as follows:

\section{$>$ Planning}

Firstly researcher has find out the problem statement of the project. In world of information where person can order a pizza, book his favorite movie tickets, book his favorite destination in just one click, then why not create the blood bank management information system, so that the person in emergency can get the information in just one click. By developing the management information system for the blood bank and develop it as web based application then it can help many people. It is very unfortunate with the blood that it cannot be manufactured but it can be transfused. It is also very sad in today's world of communication blood bank still using the traditional methods. They are doing the entries manually. It is affecting the information retrieval process. The blood bank in charge is unable to retrieve the information of past six years. Secondly the inventory is not controlled properly. There are many cases happened in which expired blood is transfused to the patient, which has the severe consequences. These things encourages researcher to develop the management information system for the blood bank. 
$>$ Analysis:

It is the very important part for developing any application. Researcher has developed the web based application for the blood bank management information system at Jhalawar District Rajasthan. In this phase of software engineering detailed scope of the functions are framed, which includes the description of the function used and the navigation of the pages. Researcher has broadly divided the application into four functions. The brief descriptions are as follows:

Donor Section:

a) Donor Entry: At the time of blood donation camp when the volunteer donor has arrived, the blood bank staff member filled the entries of the donor which includes $\mathrm{CHC}$ name, name of the donor, contact details, date of donation, number of units. After submitting the detail of the donor MIS generates the unique identification number of the donor, which is composed by his $\mathrm{CHC}$ number, date of donation and the serial number of the donor.

b) Pending Donors: After submitting the page of all the donors the information goes to the pending donor function. Practically after the collection of all the blood units in the blood donation camp these units will undergo to the medical check up for detecting the blood group and the medical status whether the particular blood group is health or not. Researcher has developed this function which helps the blood bank in charge. In this function administrator can view the details of all the donors. After getting the medical report he can select the medical status of the particular donor. He first fills the detail of the blood group and then the medical status. If the medical status is negative it goes to central inventory, if not then administrator has to first filled the reason for the positive medical status. After filling the reason it goes to discard inventory.

Seeker Section

a) Seeker Entries: As like donor details, administrator first filled the details of the seeker which include the name of the seeker, blood group required, number of units required, replacement blood donor, replacement blood group, contact details, number of units donated, name of the doctor, purpose. After filling the details it goes to edit inventory function

a) Edit Inventory: in this function MIS checks the desired blood group in the central inventory. If the desired numbers of units are available of the particular blood group then the numbers of units are dispatched to the seeker. It also shows the days left to expire of the desired blood group. Researcher has applied FIFO (First In First Out) concept which can manage the inventory properly. But in the case of blood transfusion sometime seeker required fresh blood like in case of delivery, heart surgery. In that case researcher has given the manual option for dispatching the number of units of the desired blood group.

Report Section

Administrator can generate the reports viz. donor report, seeker report and overall report monthly, quarterly, half yearly and annually.

Search Section

Administration can search the donor by using this function. If the number of units of the desired blood group is not available then administrator can provide the information of the volunteer donors staying the patient nearby place. Searching can be done blood group wise and area wise.

\section{$>$ Code}

For the development of the management information system for the blood bank of Jhalawar District, Rajasthan researcher has used MySQL as the back end, HTML as the front end, PHP as the scripting language and JAVA script for the validation.

Justification for using the Tools

The main reason for using these above mentioned tools is that it is the open source. This means that these tools and servers are freely available on the websites. Developers can freely download these tools and servers from their websites. Not a single penny is used for the purchasing of these tools and servers. If researcher goes for ASP.NET, windows tools then he has to pay handsome amount to the manufacturers of these tools, secondly if any modification has been done then its upgraded version has to be downloaded that means again money, thirdly developers can't able become a good programmer, because these tools are son much friendly that when developer type any letter, these tools shows the concern function of that letter. He doesn't know the utility of these functions.

MySQL, PHP and HTML are freely available and there is community who are working for the development and modification of these tools, secondly there is no need to join any so called institutes for hands on these tools. Any programmer can visits there free online tutorials and he will become the good programmer within one month. These features encourage the researcher to use these tools. Most important the future modification in the software can easily be done, because researcher doesn't has to purchase these tools. 


\section{REFERENCES}

1). Brooks, F., The Mythical Man-Month, Addison-Wesley, 1975.

2). Kerr, J. and R. Hunter, Inside RAD, McGraw-Hill, 1994.

3). McDermid, J. and P. Rook, "Software Development Process Models," in Software Engineer's Reference Book, CRC Press, 1993, pp. 15/26-15/28.

4). Boehm, B., "A Spiral Model for Software Development and Enhancement," Computer, vol. 21, no. 5, May 1988, pp. 61-72

5). Boehm, B., "Using the WINWIN Spiral Model: A Case Study," Computer, vol. 31, no. 7, July 1998, pp. 33-44. 